\title{
Introduction to Volume VIII
}

\author{
Ludwig Kramer and Emanuela Orlando
}

\section{Environmental principles}

The present volume is dedicated to an increasingly prominent feature in the development of environmental law: the environmental principles. Over the past decades, there has been a proliferation of such principles, reflecting the expanding scope, complexity and progressive level of maturity of environmental law. Environmental principles are included in non-binding declarations and resolutions of international organizations, as well as in international treaties, regional agreements, and domestic legislation. They are increasingly referred to in case-law across different jurisdictions at domestic, regional and international level; have attracted the growing interest of scholars and commentators, and occupy a place in (almost) every environmental law textbook.

Environmental principles vary widely in their substantive focus and orientation, often underlining different, yet partly overlapping, approaches to environmental protection and sustainability. ${ }^{1}$ They range from principles with a more specific environmental dimension, to those geared towards sustainable development and the north-south dimension of environmental governance, to others reflecting the human rights dimension of environmental protection and sustainability. Other possible categorizations in the analysis of the principles can be established between principles relevant to the notion of prevention in the broad sense, and principles and concepts relevant to considerations of balance; ${ }^{2}$ and between substantive principles and procedural principles.

This volume aims to offer a comprehensive and analytical overview of the established and emerging environmental principles, while offering insights into their role and application in different legal settings and regional contexts. The book is composed of five parts. The first part provided a general background and introduction to the topic, with chapters discussing the more conceptual and doctrinal questions concerning the nature and evolution of the principles, their relationship with legal rules and with general international law principles, and the relationship between environmental principles and the right to a quality environment. Part Two provides a selective analysis of the various individual principles as recognised in major international legal and regional instruments and international agreements. Part Three explores the development and application of environmental principles in various world regional contexts with a view to give insights on the impact of different legal cultures on the normative scope and contents of the principles. Part Four, Five and Six examine the role of the principles within the international legal context. In particular, Part Four discusses the articulation and integration of environmental principles in various multilateral environmental agreements with a view to explore their cohesive

\footnotetext{
${ }^{1}$ Scotford (2017) 78.

${ }^{2}$ Dupuy and Vinuales (2015)
} 
role across the field of international environmental law. Part Five examines the role of principles in the practice and jurisprudence of international and regional courts and tribunals. Finally, Part Six on environmental principles in international practice aims to provide an overview of the role and normative impact of the principles in selected areas of international law practice, such as in the north-south relationships; international trade and investments; and the financial policies of multilateral development banks. This part concludes with two contributions discussing environmental principles from the perspective of the different initiatives to improve compliance with environmental law and enforcement of environmental norms, and their role in the resolution of environmental disputes.

While putting together the different contributions, however, we did not aim to compile a conclusive and exhaustive account of the several principles available in the field of environmental law. There is to date no definitive and exhaustive list of the environmental principles available worldwide, although, at least from an international environmental law perspective, an authoritative indication in this sense can be found in non-binding texts-such as the Rio Declaration and the Stockholm declaration, and Agenda 21-as well as in the various attempts by expert groups and legal scholars to adopt compendia of environmental law principles. 'Environmental principles' represent an open and dynamic category, whose loose boundaries allow them to adapt and evolve to deal with changing circumstances and novel environmental problems. Thus, while some principles are nowadays well-established, others have recently entered the environmental legal dictionary, and new principles have been put forward as a consequence of the greater environmental awareness and increased understanding of environmental problems. Furthermore, alongside widely recognized environmental principles at the international law level and across different jurisdictions worldwide, ${ }^{3}$ other environmental principles have emerged in particular legal systems, reflecting the needs, aspirations and objectives of that particular culture and legal tradition. This is the case for example of the 'protection first' principle in China; ${ }^{4}$ or the public trust doctrine which, inherited from the US, is being increasingly used in environmental cases by courts in India and Sri Lanka. ${ }^{5}$ There are different reasons explaining the significant role and popularity of the principles in the environmental field. On the one hand they are related to the symbolic nature and significance of the principles, which reflect the ethic, aspirations and ideals of the society with respect to the environment. It has been argued that environmental law is a 'goal oriented discipline', 6 where principles can have a guiding function, helping to identify the goals to be pursued by environmental policies and legislation. As they are incorporated into treaties, legislative and policy instruments, principles help to translate the underlining values and ideals into legal language. In this sense, they represent the ideal bridge between ideals and duties, between values and rules,

\footnotetext{
${ }^{3}$ These include the precautionary principle, the principle of prevention, the polluter pays principle, the principle of integration, the principle of intergenerational equity, and other procedural principles, such as environemntal impact assessment, public participation.

${ }^{4}$ Zhao (in this volume).

${ }^{5}$ Atapattu (in this volume).

${ }^{6}$ See Kingston, Heyvaert, and Cavoski (2017) pag 90 (citing De Sadeleer).
} 
forging the link between the 'morality of aspiration' and the 'morality of duty'. ${ }^{7}$ Although they can be legally binding, they have also been described as 'policy ideas'. ${ }^{8}$ Indeed, it is this very essence of the principles, at the intersection between policy and law, that enables them to have an important role in forging gradually the consensus necessary to the formation and development the formation of new environmental norms. Their flexibility, and their open-ended and often indeterminate character, renders principles an attractive concept to politicians and policy-makers. Principles are helpful in forging the necessary consensus to the formation and development of new norms and, particularly at the international level, they can help negotiations being reached more easily. ${ }^{9}$ It has been suggested that it is the definitional ambiguity and flexibility that render environmental principles particularly valuable in a policy-making context, while also conferring them powerful symbolic significance. Yet, this does not preclude the fact that a given principle can gradually gain legal recognition and evolve into a legally binding norm, by effect of the judicial application or through their incorporation and formulation in prescriptive terms into the text of legislative instruments.

Principles can perform a significant role in framing the evolution and development of environmental law as a legal system. They contribute a theoretical foundation to the relatively new discipline of environmental law, while at the same time providing it with a common normative ground that transcend jurisdictional boundaries (both vertically and horizontally) to reflect the interdependent, holistic and global dimension of environmental issues. Because of their flexible and open-ended nature, and their policy oriented dimension, principles can also be particularly relevant to cope with the interdisciplinary and cross-cutting nature of environmental problems, helping to connect environmental law with other disciplines, both within and outside the legal realm. They have been described as "connecting vessels of domestic law and international law, and ... also in the relations between international environmental law and general international law, or other specialist fields of international law". ${ }^{10}$ Principles can play a systemic, integrative function and "in a context where there is growing competition among legal sectors and regimes, principles are used to overcome the negative side-effects of fragmentation". ${ }^{11}$ They can be used by adjudicatory bodies to reconcile and balance environmental protection with potentially competing interests, such as in the field of trade, thereby preserving the coherence between different branches of international law. But they can also be used to preserve the internal coherence within different regimes of environmental protection, such as in the case of biodiversity protection ${ }^{12}$ and freshwater resources. ${ }^{13}$

\footnotetext{
${ }^{7}$ Vershureen (2006)

${ }^{8}$ Scotford, (n.1), 6.

${ }^{9}$ See Bodansky (2010)

${ }^{10}$ See Fajardo del Castillo in this volume

11 Ibid.

${ }^{12}$ see chapter by Koester (in this volume).

${ }^{13}$ see chapter by Alberton (in this volume).
} 
From an international law perspective, environmental principles have contributed to the greening of some classic international law concepts; ${ }^{14}$ or to steering the progressive evolution of international environmental law from a law based on coexistence towards a new paradigm of cooperation. Early principles governing the relationship between neighbouring states have progressively been complemented by principles of cooperative management; dealing with the need of developing states; or identifying the emergence of common collective interests independently from territorial boundaries.

But what is in practice the legal significance of the principles in concrete cases? What is their role in the day-to-day practice of adjudicatory bodies; or in the decisions of public authorities? To what extent can they be considered a source of positive obligations? These and similar questions are recurring themes arising across the various chapters in this volume. Of course, it is difficult to offer a single and conclusive answer to those questions and make generally valid assumptions on the status and significance of the principles. What emerges from the different chapters in this book is indeed a variegated picture of the different principles, which highlights the wide diversity between them in terms of their respective conceptual identity, legal status and level of normative development. Although all of the concepts examined in the various contributions are referred to as principles, they constitute a rather heterogeneous group: some of them represent broad policy goals (such as sustainable development), whereas other give more defined rules and directions (such as the procedural requirement for environmental impact assessment). ${ }^{15}$ Some principles are also subject to different characterizations. Discussions abound among scholars as to whether a given principle is a concept, an objective, a framework, an approach or an instrument, thereby reflecting their often contested nature and legal status. Beyerlin has used the term 'twilight norms' to refer to the 'ever-growing number of amorphous concepts and principles' that are situated 'in the grey area between international hard law and soft law' and 'whose nature and normative quality are far from clear'. ${ }^{16}$

From an international law perspective, the incorporation of the principles into the text of international conventions and multilateral agreements can certainly provide them with specific legal relevance, albeit confined within the scope of application of the conventional regime. There can also be a difference between principles included in the preamble of international conventions, and those which instead form part of the legal provisions. Outside specific treaties, principles enter to form part of the legal sources of international law through their translation into customary rules or their recognition as general principles of international law. Yet, there is often contestation as to whether a given principle has effectively acquired customary law status, although there seem to be consensus in this sense at least with respect to some fundamental principles governing the relations between states in a transfrontier context-such as the 'no harm' principle; the principle of environmental impact assessment; the principle of notification and

\footnotetext{
${ }^{14}$ See the discussion on the principle of permanent sovereingty and on the principle of sustainable use of natural resources by Gestri and Redwgell, respectively (in this volume).

${ }^{15}$ Sands and Peel, 231; Beyerlin (2008).

${ }^{16}$ Beyerlin (2008) at 426.
} 
consultation; and a due diligence duty of prevention; as well as to other important principles, such as the principle of sustainable use of natural resources, which signal the shift towards a more sustainable approach to state sovereignty. ${ }^{17}$

In practice, the legal status, specific role, and substantive meaning of environmental principles also depend on the specific legal setting and jurisdictional context. In this sense, Scotford has argued that 'environmental principles are not universal or autonomous legal concepts...[R]ather they look very different, despite similar names, in different jurisdictions', ${ }^{18}$ so that 'the meaning and application of specific principles are only made concrete within discrete legal settings' ${ }^{19}$ Thus even similarly worded principles may assume different meanings and lead to different applications in different legal contexts. A paradigmatic example is represented by the precautionary principle whose legal status has remained widely contested at the international level, ${ }^{20}$ whereas it has been given considerable legal effect in the EU context. ${ }^{21}$

This leads to a further question, that is: when and to what extent do principles translate into legal norms and standards? To what extent can they be invoked in courts or play a role in judicial review of public authorities and private parties? One aspect that emerges from the analysis of the various principles and their application is that the mere fact that a principle is mentioned in an international agreement, or in the text of domestic legislation does not automatically mean that it will have significant legal effects or that it is enforceable. The way how a given principle is formulated, whether or not in sufficiently prescriptive terms, is an important factor. ${ }^{22}$ The very nature and the substantive contents of the principle in question are also relevant. Some principles lend themselves more easily to translate into legally binding requirements. Within the EU legal order, this is the case, for example, of the proximity principle, the principle of public participation, access to information and environmental impact assessment, which to different extent have been incorporated into EU secondary legislation and translated into legal obligations and requirements. Other principles, such as typically sustainable development, or the integration principle, are instead more vague; their nature as principle, as objectives or as ideals is still contested.

Courts and other adjudicatory bodies have an important role in clarifying and defining the legal relevance and status of the principles. The contribution by Stephens, for example, discusses the recently more active engagement of the ICJ with environmental principles, and its willingness to recognize and emphasise the relevance of procedural principles (such as notification, cooperation and environmental impact assessment), as standard for review of state parties action. ${ }^{23}$ Similarly Proells' chapter highlights the crucial role in this sense played by ITLOS in contributing to the legal recognition of certain key environmental principles-such as the principle of cooperation, prevention and precaution-both recognizing their customary law status or initiating a trend

\footnotetext{
17 See Redgwell, in this volume

${ }^{18}$ Scotford, at 5

${ }^{19}$ Ibid, at 3

${ }^{20}$ See Kulovesi and De Sadeleer in this volume.

${ }^{21}$ See Kramer, chapter n. -- in this volume.

${ }^{22}$ In this sense, de Sadeleer (2002) 368.

${ }^{23}$ see chapter by Stephens in this volume.
} 
towards making such principles part of customary international law. ${ }^{24}$ In the EU context, Kramer shows how the Court of justice 'has used the principles in concrete cases, often deducing far reaching consequences', contributing 'to give concrete content and significance to the principles enshrined in the Treaties and in secondary EU legislation' ${ }^{25}$

Courts are undoubtedly important actors in strengthening the normative force of the principles, and in paving the way towards the translation of (certain) principles into legal norms and standards. Yet, some of the chapters also reveal that, with the possible exception of the EU Court of Justice, international courts appear generally more willing to fully engage with principles of a procedural character-such as environmental impact assessment, notification, consultation, or the principles of participation ${ }^{26--o r}$ with those that embody specific requirements - such as the no harm principle, or to some extent the principle of prevention.

\section{Environmental principles and global environmental problems}

Many of the environmental principles, existing and upcoming, concern problems that are local or regional. Their large-scale use is often not clear. Yet, if one looks at the global environment, the need and/or the usefulness to recur to environmental principles also becomes obvious.

The planet's present most important environmental challenges include the threat of climate change, the loss of biodiversity, the limitation of natural resources, the omnipresence of chemicals and the need to eradicate poverty. Environmental principles, though, play a limited role in the attempts to find appropriate responses to the challenges caused by these concerns. This is different from guiding principles for the co-existence of humans on this planet: the principles that all humans are created equal, or that there is something such as a human dignity are largely recognized. Law-makers and professors, administrations and courts, governments, religious people and economists at least claim that they respect these - and other - principles of human coexistence, even when the social, economical and political reality does not reflect them.

Environmental principles have not gained this weight. Not even the best recognized of these principles such as "the polluter shall pay", the interest of future generations or the precautionary principle gained far-spread acceptance by policy-makers, judges or scientists. This becomes obvious, when the different environmental challenges are considered one by one:

As regards climate change, the principle of common, but differentiated responsibility was inserted into the international agreements to fight climate change right from the beginning of international agreements in this area. Yet, it did not prevent the United States to withdraw its signature from the Kyoto Protocol and announce its departure from the Paris Agreement on climate change. It was not even possible to agree internationally on the principle that the greenhouse gas emissions per capita should be the same all over the planet, and elaborate a working plan and a timetable to

\footnotetext{
${ }^{24}$ See chapter by Proells in this volume.

${ }^{25}$ See chapter by Kramer in this volume.

${ }^{26}$ see for example the analysis by Pedersen on the Court of Human Rights approach to the principle of participation, compared to its approach towards other principles, such as notably the precautionary principle.
} 
get there. Countries which produce fossil fuels approach the term "responsibility" (in "common, but differentiated responsibilities"), the principle of sustainable development, the "sustainable use of natural resources" or the principle of interests of future generations quite differently from other countries. And courts all over the world do not have the vision to give progressive interpretations, which would allow to gradually re-orient the interpretation and application of these environmental principles to reach greater effectiveness.

The loss of biological diversity is an accepted global phenomenon which is not seriously disputed. Yet when it comes to conflicts between economic interests - logging, mining, building of infrastructure, fishing, agricultural activities or urbanization - the natural environment is almost always the loser. No environmental principle - sustainable development or sustainable use of natural resources, environmental impact assessments or the prevention principle - has succeeded to cause a significant reduction or a stop of the loss of biological diversity.

The principle of sustainable production and consumption has not brought to halt the overproduction of goods or food in particular in developed countries, with the consequences of large waste generation. Third world countries continue to be, to a large extent, the waste-bin of developed countries; the principle of fighting environmental harm at source which implies that waste is treated and disposed of, where it is generated, has had little or no influence on streams of raw materials, products and wastes. Waste management continues to be a serious, growing problem worldwide.

Environmental pollution, caused by chemical substances in the air, in fresh and marine waters, in the soil and in food remains a serious problem for human and animal health and the protection of the environment. The substitution principle, the principle that environmental impairment should be fought at source, the polluter-pays or several other principles had no significant influence on the quantity of chemical pollution in the human neighbourhood or in the environment. Local or regional improvements of air, water and soil quality do not change the overall picture.

The eradication of poverty made some progress during the last decades, though results are questioned by the demographic development on earth as well as the increasing disparity among rich and poor countries. Principles of equity, the right to a quality environment, a sustainable development for everybody - most of the principles which are being discussed in this volume neither apply to the great majority of the poor on this planet nor do they affect them, which means that they are not helpful to improve their life and their daily fight for survival. Yet, the examples mentioned demonstrate, we believe, that environmental problems and environmental principles are not only the problems of an affluent society, but rather of human society as such.

Probably, a lawyer has to accept that "justice" in the environmental area, in particular seen in a global context, is a vague term and that progress towards this ideal must be measured by fractions of millimeters. It can only be hoped that very slowly, environmental principles will grow, become applied by courts, administrations, law-makers and law-enforcers. 
It should not be forgotten, though, that these environmental principles did not yet exist at all some sixty years ago. This means that academic thinkers and philosophers, researchers and administrators, did a very considerable work to develop environmental principles to the stage where they are at present. And the question is what can be done to make environmental principles gradually become human right principles that apply, whenever the activity of humans and its impact on the environment is weighed.

The first suggestion in this regard follows from the fact that the environment has no voice. There is no powerful lobby group behind it which could defend its interests in the daily struggle between vested interest requests and the need of ecological preservation. And in almost all social systems in the world, the protection of the environment was laid into the hands of public authorities. From this situations stems the need to have, in any administrative decision which impacts on the environment - and this includes the decision not to take action - the environmental concerns and principles discussed and weighed against the other interests at stake (integration principle). Administrative authorities should explain, why they do or do not apply the polluter-pays principle, in which way their decision takes into account the interests of future generations or why and to which extent they respected the principle of a sustainable use of natural resources. The more environmental principles are discussed, the more the chances increase that there is some justice done also for the "environment without a voice".

Environmental principles should systematically be discussed in court decisions which have an impact on the environment. Courts are established in our societies to weigh the different interests in a case and arbiter in the society's best interest. As the environment is normally not represented in court, the judge should explain how his or her decision takes into account the relevant environmental principles. He has the authority and the power to argue, how far an environmental principle can carry in a specific case. Of course, we have no illusion to believe that the judges will regularly follow this suggestion; the European Court of Justice and its - more than restricted application of the environmental principles being the best evidence for this. However, if ever environmental principles and their interpretation can contribute to finding better answers to the above-mentioned global environmental and the numerous other regional or local challenges, the principles need being discussed, polished, fine-tuned, revised, questioned and used in the daily battles for influence.

It is obvious that the defense of the environment would be much easier, if there were a wellrecognized, clear right to a clean environment. Despite, though, the numerous proclamations of such a right in constitutions, political declarations and academic studies, such a human right which would be able to stop, in a concrete case, a specific industrial, transport, infrastructure or energy project, is not in sight. All the more is it necessary to reconsider the basics of environmental protection and the function which environmental principles are capable to play.

As mentioned, in all societies, significant decisions which have an effect on the environment, are laid into the hands of public authorities: these authorities grant permits, give economic support, plan and execute infrastructure measures, draft legislation, fix standards and taxes, enforce 
provisions etc. Parliaments - where they exist - lay at best down the framework for action; but the determination of the details of interference with the environment are put into the hands of public authorities. However, these authorities are neither the owner of the environment nor are they necessarily best placed to find the appropriate balance between environmental and other interests. Political influence, vested interest lobbying, corruption - there are numerous aspects which influence the authorities' decisions. And as the voiceless environment cannot effectively defend itself, the conflicts of interest end all too often with the placing of environmental interests as a second, third or fourth priority.

This pleads for giving civil society and its representatives - individual citizens, environmental organizations, environmental ombudsmen or agencies - a much greater role in the defense of environmental interests. The 1998 Aarhus Convention on access to information, public participation in decision-making and access to justice in environmental matters paved to some extent the way which could be taken:

Decisions by public authorities which might impair the environment, should be transparent. The authorities should lay open all the documents supporting an application for a public decision, make available the studies and documents concerning the direct and indirect environmental effects of the project, lay account of the economic and financial aspects of the application and possible alternatives - including the zero-option of not agreeing to an application. The internet age allows this kind of transparency with little administrative effort. The authorities should do the utmost to make the citizens who may be affected by the envisaged measure, participate in the deliberations on the pros and cons of the measure, and bring their local know-how into the discussion. And there should be a possibility to challenge the authority's decision before a court, as courts are arbiters in the cases of diverging interests and opinions. Such access to courts would also allow to partly solve the question, who protects the environment against administrative inertia, passivity, or collusion with vested economic interests.

It is of particular importance to ensure that civil society representatives have standing in courts in environmental cases. When the public authorities are not able or not willing to protect the environment, there must be someone who takes up the challenge. It is absurd to allow the producer of a pesticide to go to court, when his application for a permit is refused, but not to allow such a court action, when the pesticide is authorized but is, in the opinion of the applicant, dangerous for the environment. It is absurd to prohibit asbestos in industrialized countries because of its dangerous properties, but to allow it to be exported to third world countries - as if the risk did not exist there; and nobody in the industrialized country is allowed to challenge the export permit in court. Numerous other examples of this kind could be given.

Such requests are future music and we are well aware of that. The United States and some Arabian countries succeeded during these last years to avert the elaboration of a sort of global Aarhus Convention. Even without such an international law instrument, the willingness to protect the environment is, prudently expressed, limited. Granting rights to civil society - even when these are only procedural rights such as established by the Aarhus Convention - reduces the power of 
existing decision-making structures. Knowledge gives power and the disclosure of documents or the citizens' participation in a given case means sharing of power - and the readiness to share power is not great anywhere.

What is even more relevant: improved rights for citizens to defend, preserve and protect the environment will not constitute the miraculous solution to solve the five big environmental problems of the planet, mentioned above, or other problems of environmental degradation. The Urgenda law-case in which for the first time a (Dutch) court found that a government did not do enough to fight climate change, was decided in June 2015. As the case is on appeal, it will take time before a final judgment is given and it is not excluded that 2020 - the date by which the Dutch Government was to achieve better results in its struggle against climate warming - will have passed. This case shows that also an environmental policy which is driven, pushed and promoted by civil society, would not escape the problem that it is comparable to the long and patient drilling of hard wood. Improvements, if they come, will come very slowly.

Yet, this perspective should not deter researchers, lawyers, academics, NGOs and committed citizens to continue their fight for better, better enforceable and better respected environmental principles. Such principles give guidance to others, private persons and public bodies. They may orient small and huge protection steps: they encourage people in continuing on their path for a better environment, allow the building up of coalitions and help establishing networks. Lawyers in particular, who look at environmental principles, should not forget that these principles are not made to only have a look at the planet's environment, but to change it for the better, and that - in paraphrasing Brecht - when they fight for a better environment, they may lose; but when they do not fight, they already lost.

We hope that this collection of contributions from all over the planet will encourage young persons, students and others, to take up the fight for a better environment, give them new ideas and inspirations. The need for taking up this fight become more obvious day by day. We are now setting the standards which apply and show their effects in 2050 or 2060 - a time, where the planet will host about ten billion humans, who all need water, energy, clean air and a healthy environment. There is no time to lose.

\section{Bibliography}

Beyerlin U, 'Different Types of Norms in International Environmental Law, policies, principles and rules' in Bodansky D., Brunnée J. and Hey E., The Oxford Handbook of International Environmental Law (OUP, 2008). 
Bodansky D., The Art and Craft of International Environmental Law (Harvard University Press, 2015)

de Sadeleer N., Environmental Principles: From Political Slogans to Legal Rules (Oxford: Oxford University Press, 2002)

Dupuy PM and Vinuales J, International Environmental Law (CUP, 2015).

S. Kingston, V. Heyvaert, and A. Cavoski, European Environemntal Law (Cambridge University Press, 2017)

Sands and Peel, Principles of Environmental Law (Cambridge University Press,

Scotford E., Environmental Principles and the Evolution of Environmental Law (Hart Publishing, 2017).

Verschuuren J., 'Sustainable Development and the nature of environemntal legal principles' (2006)

Potchefstroom Electronic Law Journal, 1-57, available at:

https://www.ajol.info/index.php/pelj/article/viewFile/43455/26990 